\title{
Double blind placebo controlled trial of short term transdermal scopolamine on heart rate variability in patients with chronic heart failure
}

Govindarajan Venkatesh, Ernest L Fallen, Markad V Kamath, Stuart Connolly, Salim Yusuf

\begin{abstract}
Objective-To test the hypothesis that short term application of transdermal scopolamine increases heart rate variability (HRV) and restores sympathovagal balance in patients with stable congestive heart failure (CHF).

Design-A double blind placebo controlled crossover study.

Setting-Tertiary referral centre.

Patients-Twelve patients (mean age 66 (10)) with New York Heart Association class II-IV CHF. All patients had coronary artery disease (mean left ventricular ejection fraction $26 \cdot 7$ (8.9) \%).

Intervention-Patients were randomly assigned to receive either a placebo skin patch or a transdermal scopolamine patch (Transderm, 0.05 mg/h). Patches remained in place for 48 hours with a 24 hour washout period before crossover.

Outcome measures-HRV was derived from (a) 24 hour time domain indices (mean RR interval, standard deviation of interbeat interval, and the baseline width of the frequency distribution of $R R$ intervals) and (b) short data set $(2 \cdot 2 \mathrm{~mm})$ power spectral measurements using autoregressive modelling. Autospectral measures were performed in both resting supine and standing (orthostatic) states. The 24 hour Holter record was obtained during the second day of patch applica-
\end{abstract} tion.

Results-There was a small but significant $(P<0.05)$ increase in all time domain HRV variables with scopolamine. There was a paradoxical fall in low frequency (LF) spectral power induced by orthostasis during baseline $(-30 \%)$ and placebo $(-34 \%)$ states. Conversely, scopolamine was associated with a $14 \%$ increase in LF power during orthostatic stress. Scopolamine thus significantly reduced the orthostatic fall in LF $(P<0.01)$ compared with either baseline or placebo values. No difference in circadian rhythm was seen between the scopolamine and placebo treatment periods. However, the abrupt fall in the high frequency (vagal) power during the early morning sleep-wake hours was reduced by scopolamine. Scopolamine was also associated with a significant rightward shift in the resting LF central frequency consistent with a vagomimetic effect.

Conclusion-Patients with chronic stable CHF showed a paradoxical fall in the low frequency (sympathetic) power during orthostatic stress. Transdermal scopolamine applied over a 48 hour period partially restored the balance between sympathetic tone and vagal activity in CHF patients and maintained this balance during orthostatic stress.

(Heart 1996;76:137-143)

Keywords: power spectrum; time domain analysis; scopolamine; left ventricular dysfunction

Though chronic congestive heart failure $(\mathrm{CHF})$ begins as a cardiac disorder there is often progression to systemic manifestations such as overcompensated neurohumoral activation, ${ }^{1}$ depression of arterial baroreceptor sensitivity, ${ }^{2}$ and depressed vagal modulation of sinoatrial activity. ${ }^{3}$ Accordingly, there is persuasive (albeit circumstantial) evidence that heightened sympathetic tone coupled with depressed cardiac vagal activity predisposes cardiac patients to unstable ventricular tachyarrhythmias and sudden cardiac death. ${ }^{45}$ Reduced heart rate variability (HRV), expressed in either time or frequency domains, is a common finding in patients with depressed left ventricular function. ${ }^{36}$ Since reduced HRV is independently predictive of cardiac death after recovery from acute myocardial infarction, ${ }^{57}$ it is postulated that patients with CHF, regardless of aetiology, may be at an equally high risk of malignant ventricular arrhythmias as a consequence of impaired autonomic tone.

It is now recognised that cardiac vagal tone can be augmented and possibly sustained by interventions such as exercise training, ${ }^{8} \beta$ blockade, ${ }^{910}$ vagoafferent electrical stimulation, ${ }^{11}$ and low dose atropine. ${ }^{12}$ Scopolamine is an atropine-like belladonna alkaloid. At high doses these drugs are anticholinergic but at low doses, their primary effect is to enhance efferent parasympathetic tone, predominantly through central nervous system mechanisms. ${ }^{13}$ Several studies have clearly demonstrated that transdermal scopolamine increases vagal tone in normal subjects as measured by both baroreceptor sensitivity ${ }^{14}$ and power spectral analysis of heart rate variability. ${ }^{15}$ Furthermore, confirmation of a vagomimetic effect of low dose scopolamine has been reported in post-myocardial infarction patients ${ }^{1617}$ as well as in those with depressed left ventricular (LV) function. ${ }^{18}$ We therefore tested the hypothesis that short term applica- 
tion $(48 \mathrm{~h})$ of transdermal scopolamine would restore the balance between sympathetic and vagal modulation of $H R V$ in patients with chronic stable heart failure.

\section{Patients and methods}

We studied 12 patients, 10 men and two women. All patients had coronary artery disease documented by a history of previous myocardial infarction, a positive exercise test, or coronary angiography. All complained of effort dyspnoea and/or effort intolerance. Four of the patients were in NYHA class II; seven in class III, and one in class IV. Their mean age was 66 (10) years and their average resting LV ejection fraction, by radionuclide angiocardiography, was $26.7(8.9) \%$. All patients were in sinus rhythm at the time of study. Patients were free of glaucoma, urinary tract obstruction, and symptomatic bradycardia. Patients continued with their usual antifailure medications throughout the study with no change in dosage. These included digoxin (77\%); ACE inhibitor $(77 \%)$, and diuretics $(69 \%)$. The study was approved by the Institutional Review Board of the Hamilton Civics Hospital of McMaster University.

\section{STUDY DESIGN AND PROTOCOL}

This was a double blind, placebo controlled, crossover study. The primary endpoints were changes in HRV expressed in both time domain indices from 24 hour ambulatory electrocardiographic (ECG) recordings and short term power spectral indices measured under steady state laboratory conditions. After they had given their informed written consent a baseline 24 hour ambulatory Holter ECG recording was obtained from the patients during free ambulation. The next morning each patient came to a climate controlled laboratory between 9 am and 11 am. Patients were asked to lie comfortably in a semi-recumbent $\left(20^{\circ}-30^{\circ}\right)$ position for 30 minutes. A continuous ECG record was obtained throughout this resting supine state while patients were allowed spontaneous respirations (the respiratory frequency was never less than $0.20 \mathrm{~Hz}$ for these CHF patients). At the end of this period the patient stood upright in a free standing posture and from the end of the first minute continuous ECG recordings were collected for 20 minutes.

Following these baseline measurements patients were randomly assigned to receive either a placebo skin patch or an identical transdermal patch containing scopolamine (Transderm, Ciba-Geigy $0.05 \mathrm{mg} / \mathrm{h}$ ) applied to the postauricular mastoid process. The patches remained in position for $48 \mathrm{~h}$ and a repeat Holter recording was obtained during the second 24 hour period. At the end of this period repeat supine and orthostatic ECG records were obtained in the same way and at the same time of day as described above. Following a 24 hour washout period, free of all patches, each patient was crossed over to receive the alternative transdermal patch and the protocol described above was repeated in an identical manner. All 12 patients completed the study.

TIME AND FREQUENCY DOMAIN PROCESSING For the time domain analysis the 24 hour Holter tape was first annotated using an Oxford Medilog Excel scanner. A beat to beat recognition software algorithm assigned a configuration class to each QRS complex. With operator assistance, differentiation and separation of normal interbeat sequences $(\mathrm{N}-\mathrm{N})$ from premature ventricular ectopic beats were performed. The normal sinus conducted $(\mathrm{N}-\mathrm{N})$ beats were then reassigned and a second software program downloaded all $\mathrm{N}-\mathrm{N}$ interbeat intervals to a floppy disk for further analysis. Three time domain variables were then computed. These included the mean $\mathrm{N}-\mathrm{N}$ interval over 24 hours, the standard deviation of these $\mathrm{N}-\mathrm{N}$ intervals (SDNN), and the base width of the frequency histogram of sequential $\mathrm{N}-\mathrm{N}$ intervals as described by Malik et al. ${ }^{19}$

The power spectrum of HRV was computed using autoregressive modelling. ${ }^{20}$ The ECG signals were passed through analogue filters with their $3 \mathrm{~dB}$ cut-off frequencies set to 1 to $100 \mathrm{~Hz}$. The filtered ECG signal was digitised using a 12 bit analogue to digital converter at a rate of $1 \mathrm{kHz}$. A beat to beat heart rate series was computed from the interval tachogram. This instantaneous heart rate series was resampled using linear interpolation to obtain an equally sampled time domain signal spaced $0.5 \mathrm{~s}$ apart. The power spectrum was then computed from the HRV data of 256 samples $(128 \mathrm{~s})$. An autoregressive model order number of 14 was fitted to the HRV signal.

Both the peak power $\left(\mathrm{bt} / \mathrm{min}^{2} / \mathrm{Hz}\right)$ and normalised area power (nu) contained in the low frequency $(0.05-0.15 \mathrm{~Hz})$ and high frequency $(0 \cdot 15-0 \cdot 40 \mathrm{~Hz})$ spectral bands were derived..$^{1021}$ In addition to being used to estimate the maximum power at specific frequencies, the peak power was also used to identify shifts in the central frequency of the low frequency band while the normalised area measurement was computed as the fractional energy contained within the integrated area subtended by each spectral band.

The autoregressive technique is applicable to short data sets but requires steady state conditions which cannot always be assured during ambulatory monitoring. Moreover, because of the reduced short term variance and autospectral energies in patients with CHF (especially under supine conditions) the low signal to noise ratio makes it difficult to be certain of any reliable effect of a given intervention. Hence, in addition to computing the power spectrum averaged over each hour throughout the 24 hour cycle, we chose to examine the orthostatic response of the heart rate autospectrum under controlled conditions thus assuring a more reliable and more reproducible deterministic low frequency signal. ${ }^{21}$

DATA ANALYSIS

Reproducibility and stationarity of the time 
Table 1 Effect of scopolamine on 24 h time domain measures of heart rate variability compared with baseline and placebo values

\begin{tabular}{llll}
\hline Time domain variable & Baseline & Placebo & Scopolamine \\
\hline Mean NN interval (ms) & $732(36)$ & $719(30)$ & $761(42)^{\star}$ \\
& $(712$ to 752$)$ & $(702$ to 736$)$ & $(738$ to 784$)$ \\
SDNN (ms) & $85(5)$ & $84(8)$ & $104(10)^{\star}$ \\
& $(82$ to 88$)$ & $(80$ to 88$)$ & $(98$ to 110$)$ \\
Baseline width (ms) & $458(44)$ & $446(37)$ & $499(51)^{\star}$ \\
& $(433$ to 483$)$ & $(426$ to 466$)$ & $(420$ to 528$)$ \\
\hline
\end{tabular}

All values are expressed as means (SD) $95 \%$ confidence intervals are given in parentheses. NN, interval of normal sinus conducted beats; SDNN, standard deviation of all $24 \mathrm{~h} \mathrm{NN}$ intervals; baseline width, width (ms) of the frequency distribution of all $24 \mathrm{~h} \mathrm{NN}$ intervals. intervals; baseline width, width $(\mathrm{ms})$ of the frequency distribution of all
${ }^{\mathrm{P}}<0.05$ when scopolamine was compared with baseline or placebo.

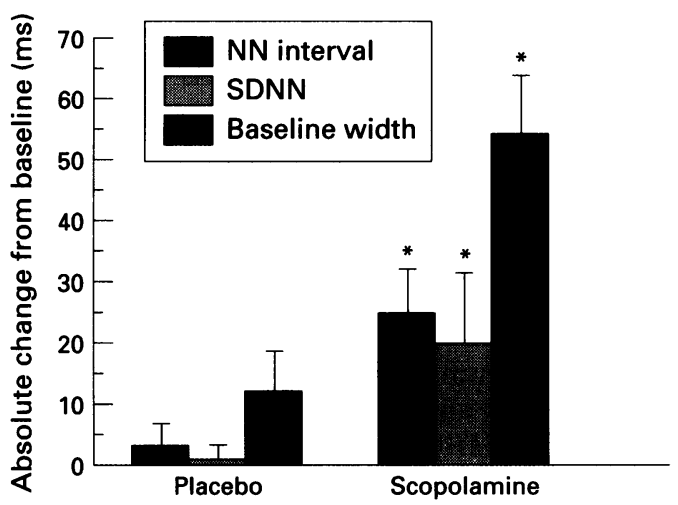

Figure 1 Absolute change in time domain indices (change in mean NN interval (ms), change in SDNN (ms), and baseline width ( $m s$ ) relative to baseline). Values are mean change (SD). ${ }^{\star} P<0.05$ compared with the change from baseline to placebo.

series measurements between baseline and placebo states were tested by computing the intraclass correlation coefficient. ${ }^{22}$ For time and frequency domain data the paired Wilcoxin and ANOVA tests were used to determine the effect of scopolamine on changes in the mean $24 \mathrm{~h} \mathrm{NN}$ interval, SDNN, the baseline width of the frequency histogram, and the autospectral indices under controlled rest supine conditions. Reproducibility of the orthostatic effect on the LF power was assessed by comparing the per- centage changes observed at baseline with those seen after the placebo patch was applied. The paired Student's $t$ test was used to determine the effect of orthostatic stress on power spectral indices in all three states. A two-sided $P$ value $<0.05$ was regarded as statistically significant. Because of the non-steady state during ambulatory monitoring no attempt was made to precisely compare the power spectra during the 24 hour cycle. However, the rate of change of the HF power from sleep to wakefulness was determined to detect any trend for scopolamine treated $v$ placebo states.

\section{Results}

TIME DOMAIN MEASURES

Table 1 shows that transdermal scopolamine was associated with a slight but significant bradycardia. The time domain measurements also showed enhanced interbeat variability with scopolamine. The standard deviation of all $24 \mathrm{~h}$ sinus conducted intervals (SDNN) was significantly higher with scopolamine, at $104(10) \mathrm{ms}$, than with the relatively low values of 84 (8) ms with placebo and 85 (5) $\mathrm{ms}$ at baseline. Similarly, the baseline width of the frequency histogram, a measure of the range of $R R$ intervals during ambulatory monitoring, was significantly wider with scopolamine at 499 (510) $\mathrm{ms}$ than with 446 (37) $\mathrm{ms}$ or placebo and 458 (44) $\mathrm{ms}$ at baseline. In fig 1 the absence of a significant change in any time domain measure while on placebo argues against any contaminating or residual effect of scopolamine after the crossover. The changes in all three time domain variables, however, were significantly increased with scopolamine.

\section{ORTHOSTATIC STRESS AND FREQUENCY} DOMAIN MEASURES

The effect of scopolamine on the short term power spectrum of $\mathrm{HRV}$ during both resting supine conditions and orthostatic stress is shown in table 2 . In the supine state scopolamine increased the average interbeat interval

Table 2 Supine and orthostatic autospectral responses to transdermal scopolamine

\begin{tabular}{|c|c|c|c|c|}
\hline Variable & Baseline & Placebo & Scopolamine & $P t$ \\
\hline \multicolumn{5}{|l|}{$\mathrm{RR}$ interval (ms): } \\
\hline $\begin{array}{l}\text { Supine } \\
\text { Standing }\end{array}$ & $\begin{array}{l}741(103)(684 \text { to } 798) \\
656(95)^{\star}(652 \text { to } 710)\end{array}$ & $\begin{array}{l}741(116)(675 \text { to } 807) \\
683(122)^{\star}(613 \text { to } 752)\end{array}$ & $\begin{array}{l}814(137)(736 \text { to } 892) \\
745(163)^{\star}(652 \text { to } 838)\end{array}$ & $<0.05$ \\
\hline \multicolumn{5}{|l|}{$\mathrm{LF}$ peak $\left(\mathrm{bt} / \mathrm{min}^{2} / \mathrm{Hz}\right)$ : } \\
\hline $\begin{array}{l}\text { Supine } \\
\text { Standing }\end{array}$ & $\begin{array}{l}67(12)(60 \text { to } 74) \\
48(13)^{\star}(41 \text { to } 55)\end{array}$ & $\begin{array}{l}66(25)(52 \text { to } 80) \\
51(27)^{\star}(36 \text { to } 66)\end{array}$ & $\begin{array}{l}56(20)(45 \text { to } 67) \\
61(22)(49 \text { to } 73)\end{array}$ & $<0.05$ \\
\hline \multicolumn{5}{|l|}{$\mathrm{HF}$ peak $\left(\mathrm{bt} / \mathrm{min}^{2} / \mathrm{Hz}\right)$ : } \\
\hline $\begin{array}{l}\text { Supine } \\
\text { Standing }\end{array}$ & $\begin{array}{l}16(10)(10 \text { to } 22) \\
27(15)^{\star}(18 \text { to } 36)\end{array}$ & $\begin{array}{l}13(6)(10 \text { to } 16) \\
33(13)^{\star}(26 \text { to } 40)\end{array}$ & $\begin{array}{l}11(8)(6 \text { to } 16) \\
24(7)(20 \text { to } 28)\end{array}$ & NS \\
\hline \multicolumn{5}{|l|}{ LF power (nu): } \\
\hline $\begin{array}{l}\text { Supine } \\
\text { Standing }\end{array}$ & $\begin{array}{l}63 \text { (7) }(59 \text { to } 67) \\
55 \text { (11) }(49 \text { to } 61)\end{array}$ & $\begin{array}{l}57(13)(51 \text { to } 63) \\
55(14)(47 \text { to } 63)\end{array}$ & $\begin{array}{l}60 \text { (12) (54 to } 66) \\
64 \text { (9) }(59 \text { to } 69)\end{array}$ & NS \\
\hline \multicolumn{5}{|l|}{ HF power $(\mathrm{nu})$ : } \\
\hline $\begin{array}{l}\text { Supine } \\
\text { Standing }\end{array}$ & $\begin{array}{l}37(8)(32 \text { to } 42) \\
45 \text { (11) (39 to } 51)\end{array}$ & $\begin{array}{l}43(13)(36 \text { to } 50) \\
45(14)(37 \text { to } 53)\end{array}$ & $\begin{array}{l}40(12)(33 \text { to } 47) \\
36(9)(31 \text { to } 41)\end{array}$ & NS \\
\hline \multicolumn{5}{|l|}{ LF:HF ratio: } \\
\hline $\begin{array}{l}\text { Supine } \\
\text { Standing }\end{array}$ & 3.34 (1) (2.77 to 3.91$)$ & $3 \cdot 1(1.9)(2 \cdot 1$ to $4 \cdot 1)$ & $2.6(1.8)(1.6$ to 3.6$)$ & $<0.05$ \\
\hline \multicolumn{5}{|c|}{$\begin{array}{l}\text { Standing } \\
\text { LF central frequency }(\mathrm{Hz}):\end{array}$} \\
\hline $\begin{array}{l}\text { Supine } \\
\text { Standing }\end{array}$ & $\begin{array}{l}0.072(0.01)(0.062 \text { to } 0.082) \\
0.071(0.01)(0.061 \text { to } 0.081)\end{array}$ & $\begin{array}{l}0.072(0.01)(0.62 \text { to } 0.082) \\
0.085(0.02)(0.076 \text { to } 0.096)\end{array}$ & $\begin{array}{l}0.082(0.01)(0.072 \text { to } 0.092) \\
0.087(0.02)(0.078 \text { to } 0.098)\end{array}$ & $<0.05$ \\
\hline
\end{tabular}

LF, low frequency; HF, high frequency. LF central frequency is the frequency at which the peak LF power occurs. Values are expressed as mean (SD). Confidence intervals $(95 \%)$ are given in parentheses.

$\star \mathrm{P}<0.05$ compared with corresponding supine value.

†Comparison of scopolamine with baseline and placebo supine states (ANOVA). 


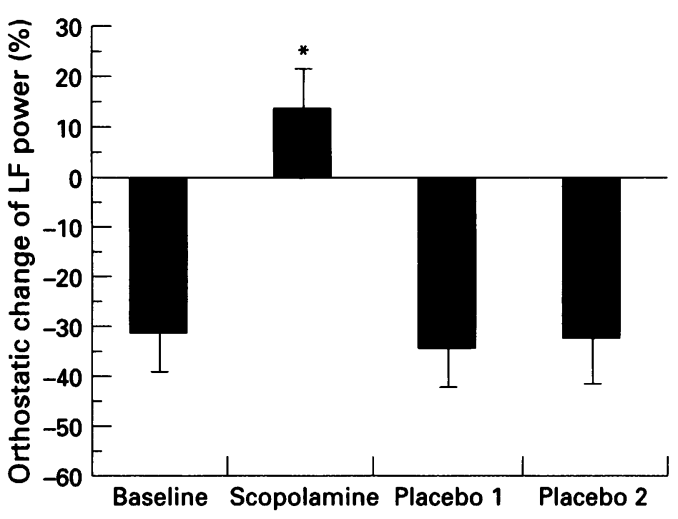

Figure 2 Percentage change in the low frequency (LF) peak power from supine to standing position during paseline, scopolamine, and placebo states. Placebo 1 and placebo 2 refer to the pre and post scopolamine phases respectively $\left(n=6\right.$ each). ${ }^{\star} P<0.05$ compared with either baseline or placebo conditions. Note the reproducibility of the orthostatic response of the $L F$ peak power between baseline and placebo states.

to $814 \mathrm{~ms}$ compared with either placebo (741 $\mathrm{ms})$ or baseline $(741 \mathrm{~ms})$. The maximum peak power in the low frequency (LF) band and the low frequency to high frequency (LF:HF) area ratio were significantly reduced by scopolamine in the resting supine state. In addition, there was a significant rightward shift in the LF central frequency from $0.072(0.01) \mathrm{Hz}$ for either baseline or placebo to $0.082(0.01) \mathrm{Hz}$ with scopolamine $(P<0.05)$.

With upright posture there was a paradoxical decrease in the LF power observed for both baseline and placebo states; 67 (12) to 48 (13) $(\mathrm{bt} / \mathrm{min})^{2} / \mathrm{Hz}$ and $66(25)$ to 51 (27) $(\mathrm{bt} / \mathrm{min})^{2} / \mathrm{Hz}$ respectively (table 2 ). Conversely, scopolamine increased LF power from $56(20)$ to $61(22)(\mathrm{bt} / \mathrm{min})^{2} / \mathrm{Hz}$. Whereas scopolamine was associated with a modest $14.2 \%$ orthostatic increase in LF power, there was a reproducible 30 to $34 \%$ drop in LF power during both baseline and placebo states respectively (table 2 and fig 2). Moreover, the

Figure 3 Stacked series of power spectra taken from one of the patients to illustrate the effect of scopolamine on the orthostatic response of the autospectrum. The individual autospectra $(2 \cdot 2 \mathrm{~mm}$ duration) are displayed as a stacked series over 15 min supine (left hand panels) and 10 min standing (right hand panels). The vertical lines denote the frequency at $0 \cdot 1$ $\mathrm{Hz}$.
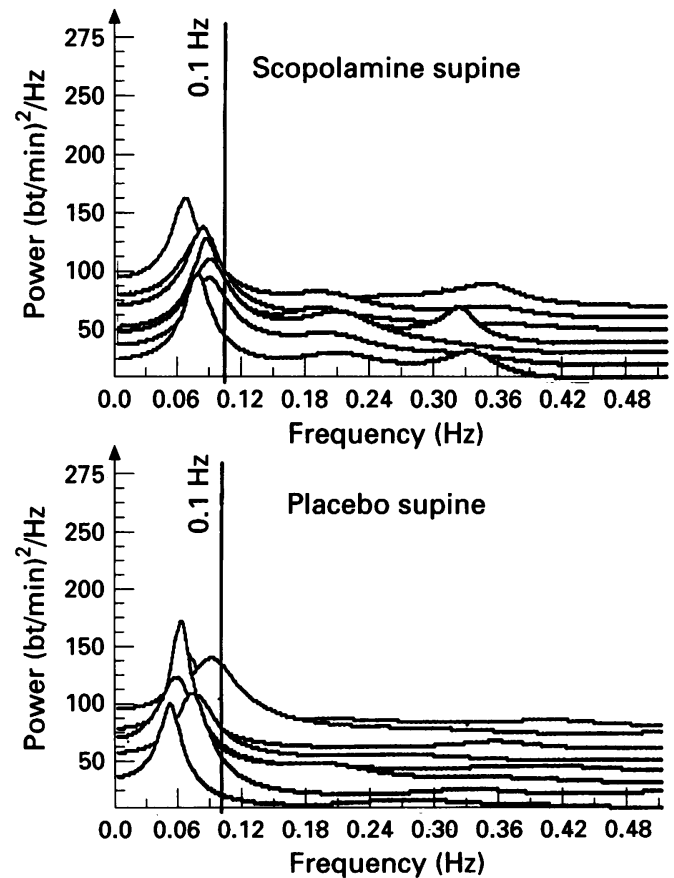

consistency in the degree of the orthostatic drop in LF power was seen whether or not the placebo phase preceded or followed scopolamine.

As an illustration of scopolamine's effect on frequency domain variables, the heart rate power spectra from one of the patients is shown in fig 3 . Sequential spectra (each $2 \cdot 2$ $\mathrm{mm}$ duration) are displayed in a stacked series over 15-20 min. These plots reveal an orthostatic fall in LF power while the patient was on the placebo patch (bottom panels). With scopolamine there is reduction in the decrease in LF power on standing. There was depressed vagal modulation ( $\mathrm{HF}$ band) regardless whether the patient was on placebo or scopolamine. Little evidence of deterministic oscillations in the vagal band was observed while the patients were taking scopolamine. There was also a rightward shift in the LF central frequency on standing, a phenomenon characteristic of the vagomimetic effects of low dose atropine. ${ }^{12}$

CIRCADIAN RHYTHM

Although scopolamine enhanced the overall variability of $24 \mathrm{~h}$ time domain indices, the autospectral pattern of circadian variation was unaffected by scopolamine (table 3). Nonetheless, for each six hours of recording the average $R R$ interval was greater and the LF:HF ratio smaller with scopolamine than with placebo (table 3). Moreover, scopolamine reduced the rapid fall in the $\mathrm{HF}$ (vagal) power during the early morning hours. This was demonstrated by the sequential percentage changes in the HF peak power during the hours of 6-10 am (fig 4). No significant changes were seen at night. At 5 am the absolute HF peak power was 32.5 (bt/ $\mathrm{min})^{2} / \mathrm{Hz}$ for placebo (squares) and $31.8(\mathrm{bt} /$ min) ${ }^{2} / \mathrm{Hz}$ for scopolamine (triangles). The graph illustrates the subsequent percentage change in the HF power during the transition
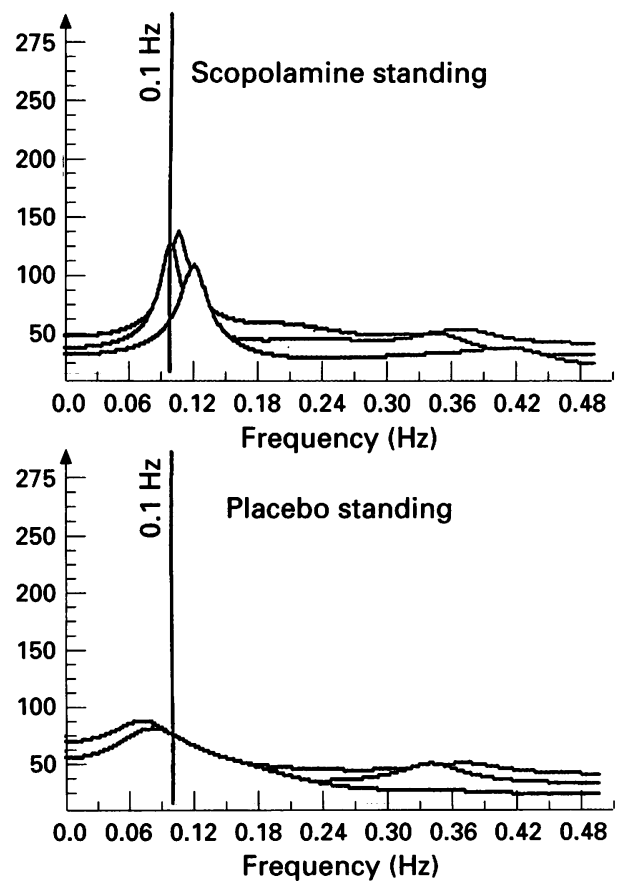
Table 3 Diurnal distribution of interbeat interval and ratio of LF:HF absolute power

\begin{tabular}{llll}
\hline Time $(h)$ & Variable & Placebo & Scopolamine \\
\hline $0300-0800$ & RR $(\mathrm{ms})$ & 745 & 798 \\
& LF:HF & $2 \cdot 72$ & $2 \cdot 14$ \\
$0900-1400$ & RR $(\mathrm{ms})$ & 695 & 704 \\
& LF:HF & $2 \cdot 74$ & $1 \cdot 89$ \\
$1500-2000$ & RR $(\mathrm{ms})$ & 698 & 746 \\
& LF:HF & $3 \cdot 54$ & $1 \cdot 75$ \\
$2100-0200$ & RR $(\mathrm{ms})$ & 740 & 796 \\
& LF:HF & $3 \cdot 80$ & $1 \cdot 87$ \\
$24 \mathrm{~h}$ avg & RR $(\mathrm{ms})$ & $719(30)(702$ to 736$)$ & $761(42)^{\star}(737$ to 785$)$ \\
& LF:HF & $3 \cdot 19(0 \cdot 67)(2 \cdot 81$ to $3 \cdot 57)$ & $1 \cdot 90(0 \cdot 80)^{\star}(1 \cdot 44$ to $2 \cdot 36)$
\end{tabular}

$\mathrm{RR}$, interbeat interval; LF:HF, ratio of absolute power in low frequency band to power in high frequency band. Values are means (SD). Confidence intervals $(95 \%)$ are given in parentheses. $\star \mathrm{P}<0.01$ for comparison of scopolamine with placebo group means.

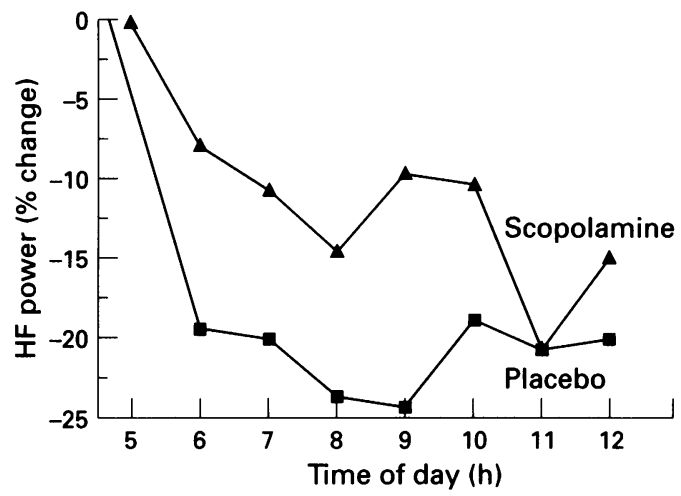

Figure 4 Successive percentage changes in the HF (vagal) power from 5 am to 12 noon in the placebo group and scopolamine group. Values are the mean percentage change for each group. The rate of decline of HF power was substantially greater for the placebo group during the early morming hours.

from sleep to wakefulness; each symbol representing the mean value for each group. The rate of change or rather the loss of $\mathrm{HF}$ power was substantially greater in the placebo group during this period.

CLINICAL EFFECTS

All patients tolerated the short term course of scopolamine. No patient experienced adverse effects sufficient to warrant drug withdrawal. One patient complained of mild drowsiness and lightheadedness while on scopolamine. There were however no haemodynamic changes and the symptoms resolved spontaneously.

\section{Discussion}

This study showed that short term transdermal scopolamine increased HRV, prevented the paradoxical fall in the LF power during orthostatic stress, and produced a rightward shift in the LF central frequency-all changes that reflect increased vagal modulation.

\section{ORTHOSTATIC STRESS}

Normally, the LF power (the spectral energy contained within the LF band) is increased at least twofold when healthy people stand up. ${ }^{1021}$ Failure to augment the LF power during orthostasis is regarded as a manifestation of impaired baroreceptor sensitivity and it is often seen in various forms of autonomic neuropathy such as diabetes. ${ }^{23}$ There are several reasons for using an orthostatic test in these CHF patients. First, it is well established that the $H R$ variance or the sum of energies contained in the frequency spectrum of heart failure patients is significantly reduced. ${ }^{3}$ This makes it difficult to dissociate, quantitatively, the deterministic cycles of physiological rhythms in the power spectrum from background noise, especially for short term data sets. For instance, in our patients the signal to noise ratio of the HF power band for any $2 \cdot 2$ min segment was extremely low (average $\mathrm{HF}$ peak power $<16 \mathrm{bt} / \mathrm{min}^{2} / \mathrm{Hz}$ ) making it difficult reliably to quantify changes in the spectral energies within the HF (vagal) band. This presents a special problem because previous studies showed that low dose scopolamine increases vagal tone in both healthy controls and those with coronary disease. ${ }^{14} 15$ On the other hand, the LF power in our subjects (average $67 \mathrm{bt} / \mathrm{min}^{2} / \mathrm{Hz}$ ) was well above noise level. Second, by using orthostatic stress to perturb integrated autonomic pathways, we were able to show a reproducible yet paradoxical orthostatic fall of $30-34 \%$ in the LF power. This abnormal decrease was prevented by scopolamine, suggesting partial restitution of autonomic control of sinus node function in patients with $\mathrm{CHF}$. Although the rightward shift in the LF central frequency was small, albeit statistically significant, it nevertheless adds support to a cardiac vagomimetic effect of scopolamine ${ }^{12}$ despite a negligible effect on HF power during short term controlled readings. When the signal was computed over a longer data set (for example, $24 \mathrm{~h}$ ) the variance was more robust but we were still unable to discern a significant change in the absolute or normalised HF power. The decrease in the average hourly LF:HF power with scopolamine indicated a reduction in sympathetic modulation during ambulatory activity.

\section{AUTONOMIC EFFECTS OF SCOPOLAMINE}

It is well established that low dose anticholinergic drugs can cause bradycardia. ${ }^{1424}$ This enhancement of cardiac vagal tone is believed to occur through an action on medullary cardiac centres. ${ }^{13}$ Others have postulated a selective action on presynaptic muscarinic receptors in nerve endings of the heart. ${ }^{25}$ Through the process of accentuated antagonism at peripheral autonomic nerve endings, ${ }^{26}$ vagal efferent drive could inhibit noradrenaline release, accounting in part for the decrease in $L F$ power.

\section{LIMITATIONS}

Rather than risk a potentially unstable state by withdrawing antifailure drugs, patients were kept on their medications which included those with known vagomimetic properties such as digoxin. Doses of these medications were maintained constant throughout the study and the double blind crossover design helped minimise any confounding interactive influence of these drugs with scopolamine. Only one dose of scopolamine was applied for a relatively short time. One would expect dosing to be an important variable especially as the 
drug has bimodal properties (that is, directionally opposite pharmacological effects on heart rate depending on dose). Here again, the crossover double blind design enabled a clear differentiation of the drug's effect on both time and frequency domain variables from that during both placebo and baseline conditions.

\section{REPRODUCIBILITY}

The average orthostatic decrease in LF power for both baseline and placebo states was remarkably consistent at $32 \%$ and $30 \%$ respectively. The intraclass correlation coefficient between baseline and placebo values was 0.683 for the $R R$ interval whereas the variability variable, SDNN, had a coefficient of $0 \cdot 859$. The supine LF normalised area had an intraclass correlation coefficient of only 0.535 , probably because of the relatively low signal to noise ratio for autospectral values in these patients. During orthostatic stress, however, the intraclass correlation coefficient improved to 0.710 . The reproducibility between baseline and placebo was seen whether the placebo phase preceded or followed the scopolamine phase. This observation is consistent with the return to baseline HRV values during washout seen in the recent study by La Rovere et al. ${ }^{18}$ The study by La Rovere et al also used both time and frequency domain variables which demonstrated augmented vagal activity with short term transdermal scopolamine. The calculated LF:HF ratio in their baseline study averaged 1.26 compared with 3.34 in our group. This could mean that our patients had more advanced heart failure despite similarities in ejection fraction. It may also explain their ability to measure a more robust $\mathrm{HF}$ power in their group. Nonetheless, our studies are complementary in showing a similar vagomimetic effect of scopolamine in patients with impaired LV function.

\section{CLINICAL RELEVANCE}

It is of interest that those treatments that seem to prevent clinical deterioration in $\mathrm{CHF}$ patients (ACE inhibitors, $\beta$ blockers, and digoxin) have antiadrenergic or vagomimetic properties. By contrast, the temporary haemodynamic improvement seen with sympathomimetic or other inotropic agents occurred at the expense of shortened survival. ${ }^{27}$ The positive cardiac vagomimetic effects of transdermal scopolamine raises several questions. First, can patients with depressed LV function tolerate the drug?28 If so, for how long? Second, can its beneficial autonomic effects be sustained over time? Third, because the drug has opposite effects on heart rate depending on dosage, is there a safe therapeutic window for patients with impaired circulatory dynamics? Fourth, is the degree of increase in vagal activity sufficient to be antifibrillatory? ${ }^{29}$ Finally, if the above questions yield encouraging answers, can scopolamine reduce morbidity and mortality in patients with heart failure? The results of our study may be a small step towards resolving some of these important clinical issues.
In conclusion, three observations are worthy of note. First, a paradoxical fall in the LF power during orthostatic stress confirmed impaired sympatho-vagal balance in these CHF patients. Second, transdermal scopolamine applied over a 48 hour period partially restored autonomic balance in patients with chronic stable heart failure by increasing HRV and reducing the orthostatic fall in LF power. Third, orthostatic stress may prove to be a useful manoeuvre in testing autonomic function in patients with CHF or autonomic neuropathy where the power spectrum contains low energy signals at rest.

We thank Lynda James for the preparation of the manuscript. This study was supported by a grant from the DeGroote Foundation.

1 Packer $M$. Neurohumoral interactions and adaptations in congestive heart failure. Circulation 1988;77:721-30.

2 Eckberg DL, Drabinsky M, Braunwald E. Defective cardiac parasympathetic control in patients with heart disease. N Eng f Med 1971;285:877-83.

3 Saul PJ, Arai Y, Berger RD, Lilly LS, Colucci WS, Cohen RJ. Assessment of autonomic regulation in chronic congestive heart failure by heart rate spectral analysis. $A m \mathcal{F}$ Cardiol 1988;61:1292-9.

4 Schwartz P, La Rovere MT, Vanoli E. Autonomic nervous system and sudden cardiac death. Circulation 1992:85 suppl II:77-91.

5 Kleiger RE, Miller JP, Bigger JT (Jr), Moss AJ and the Multicentre post-infarction research group. Decreased heart rate variability and its association with increased mortality after acute myocardial infarction. $A m \mathcal{f}$ Cardiol 1987;59:256-62.

6 Nolan J, Flapan AD, Capewell S, MacDonald TM, Neilson JMM, Ewing DJ. Decreased cardiac parasympathetic activity in chronic heart failure and its relation to left ventricular function. Br Heart $\mathcal{F}$ 1992;67:482-5.

7 Malik M, Camm AJ. Heart rate variability. Clin Cardiol 1990;13:570-6.

8 Coats AJS, Adamopoulos S, Radaelli A, McCance A, Meyer TE, Bernardi L, et al. Controlled trial of physical training in chronic heart failure: exercise performance, hemodynamics, ventilation and autonomic function. Circulation 1992;85:2119-31.

9 Cook JR, Bigger JT, Kleiger RE, Steinman RC, Rolnitzky LM, Fleiss JL. Effect of atenolol and diltiazem on heart rate variability in normal persons. $\mathcal{F} \mathrm{Am}$ Coll Cardiol 1991;17:480.

10 Pagani M, Lobardi F, Guzetti S, Rimoldi O, Furlan R, Pissinelli $\mathrm{P}$, et al. Power spectral analysis of heart rate and arterial pressure variabilities as a marker of sympathovagal interaction in man and conscious dog. Circ Res 1986;59:178-93.

11 Kamath MV, Upton ARM, Tallala A, Fallen EL. Neurocardiac responses to vagoafferent electrical stimulation in humans. PACE 1992;15:1581-7.

12 Weise F, Baltrusch K, Heydenreich F. Effect of low dose atropine on heart rate fluctuations during orthostatic load: a spectral analysis. F Auton Nerv Syst 1989;26: 223-30.

13 Katona PG, Lipson D, Dauchot PJ. Opposing central and peripheral effects of atropine on parasympathetic cardiac peripheral effects of atropine on parasympat
control. Am $\mathcal{F}$ Physiol 1977;232:H146-51.

14 Dibner-Dunlap ME, Eckberg DJ, Magid NM, CirtronTrevino NM. The long-term increase of baseline and reflexly augmented levels of human vagal-cardiac nervous reflexly augmented levels of human vagal-cardiac nervous
activity induced by scopolamine. Circulation 1985;71: activity ind

15 Vybiral T, Bryg RJ, Maddens ME, Bhassin SS, Chronin S, Boden WE, et al. Effects of transdermal scopolamine on heart rate variability in normal subjects. Am $₹$ Cardio 1990;65:604-8.

16 Casadei B, Pipilis A, Sessa F, Conway J, Sleight P. Low doses of scopolamine increase cardiac vagal tone in the acute phase of myocardial infarction. Circulation 1993; 88:353-7.

17 Pedretti R, Colombo E, Sary Braga S, Caru B. Influence of transdermal scopolamine on cardiac sympathovagal interaction after acute myocardial infarction. $A m \mathcal{F}$ Cardiol 1993;72:384-92.

18 La Rovere MT, Mortara A, Pantalo P, Maestri R, Cobelli F, Tavazzi L. Scopolamine improves autonomic balance in advanced congestive heart failure. Circulation 1994 90:838-43.

19 Malik M, Farrell T, Cripps T, Camm AJ. Heart rate variability in relation to prognosis after myocardial infarction: Selection of optimal processing techniques. Eur Heart f 1989;10:1060-74.

20 Kay S, Marple SL. Spectrum analysis: a modern perspective. Proc IEEE 1981;69:1380-8.

21 Fallen EL, Kamath MV, Ghista DA. Power spectrum analysis of heart rate variability: a non-invasive test of integrated neurocardiac function. Clin Invest Med 1988; 11:331-40. 
22 Shrout PE, Fleiss JL. Intraclass correlations: uses in assessing rates reliability. Psychol Bull 1979;86:420-8.

23 Bianchi A, Bontempi B, Cerutti S, Gianogho P, Comi G, Natali Sora MG. Spectral analysis of heart rate variability signal and respiration in diabetic subjects. Med Biol Eng Comput 1990;28:205-11.

24 Raczkokwska M, Eckberg DL, Ebert TJ. Muscarinic cholinergic receptors modulate vagal cardiac responses in cholinergic receptors modulate vagal

25 Loffelholz K, Pappano AJ. The parasympathetic neuroef fector junction of the heart. Pharm Rev 1985;37:1-24.

26 Levy MN. Cardiac sympathetic Fedn Proc 1984;43: 4598-2602.
27 Packer M, Carver JR, Rodcheffer R, Ivanhoe RJ, Dibianco R, et al for the PROMISE Study Research Group. Effect of eral milrinone on mortity in failure. N Eng f Med 1991;325:1468-75.

28 Pedretti RFE, Colombo FE, Braga SS, Ballardini L, Caru B. Effects of oral pirenzepine on heart rate variability and baroreceptor reflex sensitivity after acute myocardial infarction. I Am Coll Cardiol 1995,25:

29 Hull SS, Vanoli E, Adamson PB, DeFarrari GM, Foreman $\mathrm{RD}$, Schwartz PJ. Do increases in markers of vagal activity imply protection from sudden death? The case of scopolamine. Circulation 1995;91:2516-9.

\section{Right to left thromboembolism through a patent foramen ovale}

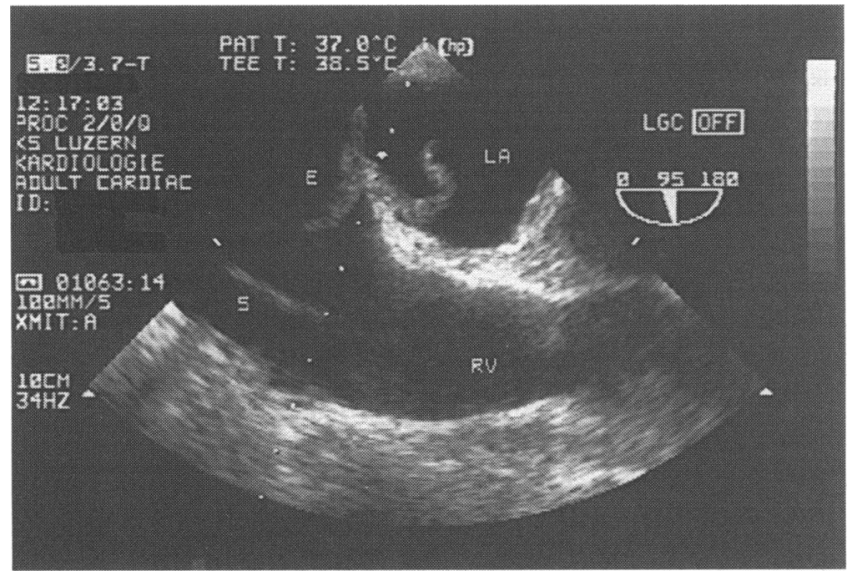

$R V$, right ventricle; $S$, Swan-Ganz catheter.
The possibility of right to left thromboembolism through a patent foramen ovale in patients with systemic embolism with no other cause continues to be discussed. We report a 63 year old man in whom we found an embolus (E) in the patent foramen ovale membrane, with one end in the right atrium and the other end in the left atrium (LA). The transoesophageal examination was done with a multiplane probe in the intensive care unit, because of a deterioration in respiratory variables in a ventilated patient after abdominal surgery.

MICHEL ZUBER PAUL ERNE 